\title{
Creativity in Higher Education; A Way to Achieve Sustainable Development in Afghanistan
}

\section{OPEN ACCESS}

Manuscript ID:

EDU-2020-09013501

Volume: 9

Issue: 1

Month: December

Year: 2020

P-ISSN: 2320-2653

E-ISSN: 2582-1334

Received: 20.10 .2020

Accepted: 25.11.2020

Published: 01.12.2020

Citation:

Mohammadi, Mohammad.

"Creativity in Higher

Education; A Way to

Achieve Sustainable

Development in

Afghanistan." Shanlax

International Journal of

Education, vol. 9, no. 1, 2020, pp. 51-55.

DOI:

https://doi.org/10.34293/

education.v9i1.3501

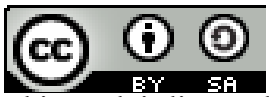

This work is licensed under a Creative Commons Attribution-ShareAlike 4.0 International License

\author{
Mohammad Mohammadi \\ Master of Education, University of Pune, India \& \\ Contract Lecturer, Herat University, Heart, Afghanistan \\ (D) https://orcid.org/0000-0002-3056-4726
}

\begin{abstract}
In the new age and the conflict of competition between societies, the superiority of countries depends on the extent to which they benefit from modern science and knowledge, and ultimately the scientific effort and technology that generates creative and efficient human resources as the main factor Finding development. Higher education represents an important type of investment in human resources and contributes to sustainable development by providing and promoting the knowledge, skills and attitudes needed by learners. Higher education promotes knowledge and new research and scientific advances. And this new knowledge owes much to human creative thinking. Therefore, creativity is one of the most important and pervasive human activities. Higher education as a manifestation of the culture of any society has a great role in the dynamism and creativity of learners. Looking at the events of the last hundred years in Afghanistan, we will know that what should have been considered in the educational centers has not been observed. A severe blow has been dealt with the various economic, social, political and cultural sectors of Afghanistan. The purpose of this article is to introduce creativity in higher education and examine its role in sustainable development to raise the attitude of educators. Because the key to cultural education, which is the key to the development and progress of society, must be found in the hands of novice and innovative teachers who believe in different creative teaching patterns.
\end{abstract}

Keywords: Creativity, Higher education, Sustainable development, Culture, Educational strategies, Afghanistan

\section{Introduction}

Undoubtedly, universities will be the main players in the third millennium, with new ideas and thoughts injecting new force into the vital arteries of society at all times; in other words, the best places to address and theorize ideas, Are universities; Higher education centers can contribute to the economic, social, cultural and political development of countries. Universities in Afghanistan play a key role in sustainable development and balancing the various dimensions of development. In this post-industrial era, creativity is not only a necessity but also a condition for survival. Despite the important and pervasive nature of creativity, education researchers have seldom considered it. Development is a set of changes that cause a social system of certain living conditions to be undesirable. Move towards better conditions. The issue of creativity and innovation has recently attracted the attention of many thinkers and officials of different societies, especially developing societies. The replacement of a static education system with an education system Dynamic and creative, which is based on childbirth, has received special attention. The effects of higher education in Afghanistan can be divided into three categories; Study effectiveness, cognitive effect, and innovation. Effectiveness enables human resources to perform their duties with more quantity and quality. 
The cognitive effect is to make and make a decision; the effect of innovation is the third effect expected to be provided through higher education. The innovators of today's world are often brought up in academic settings. Given what has been said, the purpose of writing this article is to explain the role of higher education in fostering creativity and, thus sustainable development, and that the element of culture has played a key role.

\section{The Concept of Development and Sustainable Development}

The word development entered the English language in the seventeenth century and was first used by biologists instead of the organic process. The term development has been around for almost the second half of the twentieth century. From an economic point of view, development means the national economic ability to create and maintain the annual growth of GDP. And in its parameters such as per capita income, industrial production, etc. are considered as determining factors. Development was defined as the growth of the social system as a whole, in harmony with the basic needs of individuals and social groups within society, and the transformation of the unfavorable situation of the past into a desirable situation. Hence, the development includes all factors affecting the improvement of living conditions, i.e. economic, social, cultural and political factors. Today, the focus of development is on culture, information and the development of capabilities. In other words, development is a movement towards a state of value that may be achieved in a social structure. In the approach of sustainable development and giving importance to quantitative economic variables, the quality aspects of human life are also considered. For example, we can refer to the indicators of sustainable development (education, employment, social structure, etc.) introduced by the United Nations.

\section{Definition of Creativity}

Numerous definitions of creativity have been offered by scientists; for example: Tony Bazan called creativity "reaching new ideas to solve problems, using the power of the mind and physical powers to address a multitude of ideas and behaviors." Has defined. "The ability to solve problems in a way that one has never learned to solve before," Weisberg and Weir said in defining creativity. Kraft defines creativity as "an imaginative activity to produce results that are both pure and original and valuable." "Creativity is the ability to generate new and innovative ideas, theories, insights, or phenomena and to reconstruct them in science and other fields that are valued scientifically, aesthetically, technologically, and socially," says Vernon.

\section{The Importance and Necessity of Fostering creativity in Higher Education}

The superiority of a country depends more on how it benefits from science and technology and on the dynamism of its higher education system than on natural resources or existing industrial capacities. Higher Education in all developing countries faces two major challenges:

1. Underdevelopment "means illiteracy, poverty, disease, malnutrition and unemployment, and the task of higher education is to guide and nurture graduates for socio-economic development."

2. Globalization "means the interdependence of countries and competition."The task of higher education here is to prepare graduates to deal with the ill effects of globalization and to enable them to compete with their opponents."

The only way to face these two challenges is to acquire new teaching methods, use them and pay real attention to fostering creativity in higher education, which is the main path to sustainable development. The results of Alan Chuck's research are mentioned about creating a creative attitude in graduates; During his research, he found that with special planning, it is possible to change the attitude of graduates towards school, creative processing and self-confidence. The results of this research are in line with the results of Midor research. Researchers in the evolutionary and social psychology of creativity have questioned how this ability manifests itself during adulthood. Based on his knowledge of the environment in biology, Hallington expresses his social theory of creativity: Just as in an ecosystem, living things are related to each other and their ecosystem, so in the creative ecosystem, all members and aspects of the environment They are interacting. Higher education 
institutions have a unique freedom to develop new ideas and comment on society and contribute to the creation of new knowledge. Universities must develop in their student's competencies that enable them to deal with uncertain circumstances, situations with uncertainty and contradictions, or at least with anomalies, values, and divergent interests.

\section{The Role of Culture in Promoting Creativity and Sustainable Development}

One of the important dimensions of sustainable development is the fertility of the culture that governs society because the precondition for any development is cultural development. The impact of socio-cultural climate on creativity is such that researchers believe that newly independent societies independent of foreign colonization, revolutions, wars and national upheaval can have positive and negative effects on creativity in any society. This finding is consistent with a set of experimental results. Higher education as a manifestation of the culture of any society has a great role in the creative dynamics of its learners.

Development in all its dimensions is strongly influenced by cultural beliefs. Therefore, we can understand the importance of cultural education in the education system, which is the most important strategic device to achieve the desired cultural status. In the current education system, direct teaching methods (often lecture methods) are common. These methods involve the inactivity of learners in the teaching-learning process and follow a set of undesirable cultural characteristics such as submission and submission to the existing conditions, lack of desire and diligence to learn and learn and share with others in solving social problems. Therefore, to deal with such situations, it seems necessary to choose the appropriate educational strategies:

1. Flexibility: Due to the uniqueness of each learner, to adapt their educational methods with their knowledge of the learner and his social and cultural conditions.

2. Mental exploration: Instead of giving a lot of information to the learner, they should be guided to search for information. Leaving learners free to comment and express ideas can be a good exercise for mental exploration and ideation.
3. Pay attention to the quality of thinking: The best and most creative thought and the solution is not achieved quickly, and in many cases, requires thinking with reflection instead of instant thinking. As a result, they do not expect the learner to answer the question very quickly, without thinking and considering its various aspects.

4. Paying attention to the quality of learning: While emphasizing the importance of the information learned, special emphasis should be placed on the quality of learning, especially multidisciplinary learning, so that learners pay attention to macro perspectives and their own views and analysis.

\section{The Role of Higher Education in Promoting Creativity and Sustainable Development}

The higher education system has an essential role in sustainable development and creating a balance between different dimensions of development. Principled investment in this sector is the creation of facilities and facilities for future generations and the right action for the scientific development of the country. In parallel with this investment, the reasonable expectation of society from the higher education system is to play a principled and effective role in the structure of sustainable development. What needs to be considered here is whether education affects creativity. To answer this question, we refer to Piaget's point that whenever we teach something to a child, we prevent him from discovering or inventing it himself.

Creative education plays a thirsty role, not a watering one! Such education takes the mind out of balance to achieve balance through the principle of equilibrium. In other words, the end of science is the design of ambiguous situations, problemsolving, ignorance, confrontation with the unknown, imbalance of mind, etc. The power of creativity, invention, discovery, exploration and research appears in the individual. The learner must face the problem directly and explore the relationships, processes, and analyzes. Supporting this educational method at the level of secondary education and university and then at the level of the open society, allows for creativity and self-realization. 
The higher education system in Afghanistan needs a fundamental change, but before any change, there must be a fundamental change in the attitude towards higher education. In other words, universities should not be seen as degree-producing institutions but as institutions that produce science and innovation in technology and creativity. Creativity encompasses various dimensions, including physical condition, emotional relationships between individuals, scientific and educational facilities, the motivation of teachers, design of classroom space such as sitting style, etc. Classroom atmosphere, teacher teaching method, student motivation and research spirit are very important factors in creativity and as a result, the production of thought and science. Undoubtedly, teachers play an important role in fostering and creating creativity in learners. Therefore, the following is recommended to teachers and curriculum planners in higher education institutions:

1. Paying attention to individual differences: Since some people have instant thinking and others have contemplative thinking, teachers should pay special attention to the individual differences of their students in different fields of upbringing and education.

2. The combined use of divergent thinking and convergent thinking: Teachers who allow creative thinking to occur to the learner use divergent thinking called creative thinking or horizontal thinking, along with convergent thinking. In convergent thinking, the mind chooses one of several solutions. But in divergent thinking, as opposed to convergent thinking, the mind is concerned with seeking all possible solutions to a problem.

3. Using the method of free and reciprocal discussion: Teachers who allow learners to express creative thinking use their spontaneous words and free and reciprocal and non-formal dialogue a lot.

4. Using the active teaching method: Teachers who allow learners to express creative thinking emphasize the correct use of comprehensive sensory-analytical mechanisms in learning.

5. Using the brainstorming method: Teachers who allow learners to develop creative thinking use the brainstorming method to increase the flexibility and fluidity of the mind to generate more and, at the same time, new ideas.

6. Use of direct experiences: Teachers who allow learners to express creative thinking while sensitizing learners to environmental stimuli provide them with the right conditions to manipulate objects, experiment and experiment directly.

\section{Conclusion}

In Afghanistan, universities play an important role in training the specialized and needed personnel of the country; On this principle, comprehensive and profound changes in the higher education system and the selection of effective programs will be the key to the survival and development of the country. Given that educators, as an essential element of the educational system, have an essential role in fostering creativity, it is appropriate that educational planners, implementers, and policy makers pay special attention to their selection and preparation. Despite the close and effective relationship between the higher education system and the quality of sustainable development, less research has been done in this field. Therefore, the key to cultural education, which is the key to the development, progress, and development of society, must be found in novice and innovative teachers who believe in the use of different teaching models. To this end, adopting sensible strategies and proper investment in human resource training will lead to an increase in skilled labor, with higher education, as well as an increase in researchers and entrepreneurs.

\section{References}

Albrech, K. The Creative Corporation, Dow JonesIrwin, 1987.

Alexander Robin, et al. Curriculum Organization and Classroom Practice in Primary Schools - A Discussion Paper, DES, 1992.

Asborne, Alex. Fostering Public Talentfor Innovation and Creativity, Niloufar Publications, 1386.

Beetlestone, Florence. Creative Children Imaginative Teaching, Open University Press, 1998.

Bohm, David. On Creativity, Routledge, 1998.

Buzan, Tony. The Power of Creative Intelligence, Thorsons, 2001. 
Cortese Anthony. Education for Sustainability: The Need for a New Human Perspective, Second Nature, 1999.

Craft, Anna. Creativity across the Primary Curriculum: Framing and Developing Practice, Routledge, 2000.

Fakohi, Naser. Anthropology and Development, 1382.

Gardner, Howard. Creating Minds: An Anatomy of Creativity as Seen through the Lives of Freud Picasso, Stravinsky Eliot, Graham and Grandhi, Basic Books, 1993.

Hallington, D.M. "The Ecology of Human Creativity: A Psychology of Perspective.", Theories of creativity, Sage, 1990.

Haqiqi, Mohammad Ali, and Rahimi Nik Azam. Organizational Behavior Management, 2001.

Harrison, David. Sociology of Modernization and Development, Routledge, 1988.

Hossein, Azimi. Underdeveloped Circuits in the Iranian Economy, Sharafi Publications, 1992.

Iranmanesh, Mehdi, and Ehsan Kamrani. The Role of Higher Education in Sustainable Development, Higher Education Research and Planning Institute, 1383.

Kandgon, Peterg. "The Need to Identify Gifted Children." Brilliant Talent Magazine, vol. 4, 1371, pp. 58-71.

Karimi, Abdul Azim. "Creativity Barrier Training." Journal of Management in Education, vol. 41, no. 2, 1373, pp. 27-41.

Khalili, Azam. Fostering Creativity in Children, Cultural and Artistic Institute, 1382.
Lambert, W.E., et al. "Cognitive and Attitudinal Consequences of Bilingual Schooling." Journal of Educational Psychology, vol. 65, no. 2, 1973, pp. 141-159.

Mahmood, Abdul Ali. Sociology and Social Development in Iran, 1373.

Mohammadi, Mohammad. University Education Strategies for National Development, 2020.

Piaget, Jean. The Origins of Intelligence in Children, International Universities Press, 1992.

Piaget, Jean. Where does Education go?, University of Tehran Press.

Shahr Arai, Mehrnaz. Characteristics of Breeders of Dynamism and Creativity, 1374.

Shaughnessy, Michael F. "An Interview with E. Paul Torrance: About Creativity." Educational Psychology Review, vol. 10, 1998, pp. 441-452.

Shaykhs, Farida. Educational Planning Process, Madrasa Publications, 1382.

Simontin, Dean K. "Creative Productivity: A Predictive and Explanatory Model of Career Trajectories and Landmarks." Psychological Review, vol. 104, no. 1, 1997, pp. 66-89.

Sternberg, Robert J., and Todd I. Lubart. "Investing in Creativity." American Psychologist, vol. 51, no. 7, 1996, pp. 677-688.

Todaro, Michael P. Economic Development in the Third World, 1370.

Vernon, P.E. "The Nature-Murture in Creativity." Handbook of Creativity, edited by John A Glover, et al., Springer, 1989.

Woods Peter. Teacher Skills and Strategies, Falmer Press, 1990.

\section{Author Details}

Mohammad Mohammadi, Master of Education, University of Pune, India \& Contract Lecturer, Herat University, Afghanistan 